\title{
Sex ratio bias in postpartum-conceived Norway rat litters is produced by embryonic loss in midpregnancy
}

\author{
S. J. Bacon ${ }^{1 *}$ and M. K. McClintock ${ }^{2}$ \\ ${ }^{1}$ Department of Organismal Biology and Anatomy, University of Chicago, 1025 East 57th Street, Chicago, IL 60637, USA; and \\ ${ }^{2}$ Department of Psychology, University of Chicago, 5730 South Woodlawn Avenue, Chicago, IL 60637, USA
}

\begin{abstract}
In rats, dams that conceive in their postpartum oestrus and then lose their firstborn litter bias the sex ratio of the litter toward females in utero. The present study identifies the source of litter sex ratio bias in these postpartum pregnant non-lactating dams. The female bias arises first through the postconception loss of embryos, and second, the loss occurs in midpregnancy between the attachment of the blastocyst to the uterine wall on day 5 and full metrial gland development on day 14 . Some pregnancies were restricted to one uterine horn to see if this loss (and thus the opportunity for litter sex ratio biasing) was influenced by local factors operating within the uterine horn. Embryonic loss was more closely associated with the number of embryos implanting in a single horn than with the number implanting in the litter, demonstrating that local crowding within a horn is sufficient for the preferential loss of male embryos. This loss did not cause an obvious decrease in the size of the live-born litter because only those horns with a surfeit of embryos lost them. This process was the same in the right and left horns; both carried and lost the same numbers of embryos. A dam that conceives in her postpartum oestrus and then loses her suckling litter forgoes the implantation delay and uterine healing caused by lactation. Male embryos are less successful at implanting in a uterus only recently vacated by a previous litter.
\end{abstract}

\section{Introduction}

In mammals, a large proportion of the offspring conceived does not survive to birth. It has been estimated that $50-75 \%$ of human conceptions die prenatally (Roberts and Lowe, 1975; Warburton, 1987), the majority early in pregnancy, before the end of the embryonic period (Miller et al., 1980; Edmonds et al., 1982). Non-human mammals also show high rates of prenatal loss. In cattle, $35 \%$ of recognized conceptuses die before the third month of gestation (Wathes 1992), most during early embryogenesis (Diskin and Sreenan, 1980; Roche et al., 1981). It has long been known that, after an otherwise fertile mating, one-third of mouse and rat ova do not produce young (MacDowell, 1924; Long and Evans, 1921).

Individuals of one sex can be lost preferentially, thus biasing offspring sex ratio. Prenatal loss due to maternal social subordination or nutritional stress is greater for male than for female offspring in red deer (Kruuk et al., 1999) and hamsters (Pratt et al., 1989), but females are preferentially lost in coypus (Gosling, 1986). While the theoretical framework for offspring sex ratio bias has long been clear (Trivers and Willard, 1973), specific examples of bias in mammals proved elusive until the role of prenatal loss in effecting bias was

\footnotetext{
* Present address: Department of Biological Sciences, Mount Holyoke College, South Hadley, MA 01075, USA.

Revised version received 18 June 1999.
}

clarified (Hornig and McClintock, 1994). Any systematic bias of the sex ratio imposed after fertilization can be due only to prenatal loss since, after conception, a mother can neither add individuals to her litter nor change the sex of those present (MacDowell and Lord, 1926; Hornig and McClintock, 1994). While preconception mechanisms of sex ratio biasing are also well documented in humans (Guerrero, 1974; Harlap, 1979; James, 1980) and rodents (Hedricks and McClintock, 1990; Huck et al., 1990; Hornig and McClintock, 1996), they are distinct from the postconception mechanisms investigated here.

In rats, the sex ratio of the second litter of a dam can vary as a factor of the survival of the firstborn litter (Bacon and McClintock, 1994). Female rats will ovulate and conceive within hours of parturition, and thus can carry a second litter while nursing the first. Dams lactating while pregnant give birth to litters with a sex ratio at parity, while dams that do not lactate during their postpartum pregnancy have litters with a significantly female-biased sex ratio (Blumberg et al., 1992). The lactating condition of dams was manipulated by removing the firstborn (suckling) litter one day after postpartum mating and fertilization to mimic the natural litter loss that can occur through inter-litter competition (Mennella et al., 1990; Blumberg et al., 1992), cannibalism, predation, or an insufficient milk supply (Calhoun, 1962), so any effect on the sex ratio of the litter in utero could only have been due to the postconception loss of embryos or fetuses. 
On the basis of the distribution of metrial glands at postpartum necroscopy of rats, more than one quarter (29\%) of postpartum-conceived litters were shown to be carried in only one of the two uterine horns (Bacon and McClintock, 1994). These unilaterally implanted litters were strongly biased toward females, with a mean sex ratio (proportion male) of $0.26 \pm 0.05$, compared with $0.49 \pm 0.09$ in like-sized bilaterally implanted litters. However, a lack of clear data on fetal loss precluded an analysis of its role in creating the bias.

In the present study, oestrous condition and one-horned pregnancy are examined as mediators of loss and sex ratio bias. Specifically, the circumstances in which the female bias was originally manifest were recreated by (a) removing newborn litters from their postpartum pregnant mothers 1 day after mating, and (b) inducing a set of these litters to attach and implant in one horn only. The aim of the study was to identify the stage of pregnancy at which loss imposes a sex ratio bias on postpartum oestrus-conceived litters.

Restricting the litter to one uterine horn makes it possible to address two further questions. First, are there any underlying right-left asymmetries between the uterine horns in the sex ratio of the litter carried, as has been reported in rats (Bacon and McClintock (1994), gerbils (Clark et al., 1994) and rabbits (YoungLai et al., 1981)? Second, is embryonic loss (and thus the opportunity for postconception sex ratio biasing) a factor of the number of embryos attaching per horn or per litter? Some factors affecting fetal development affect the entire litter (for example, maternal stress: McClure, 1981; lactation: Krackow, 1990; and progesterone deficiency: Huck et al., 1988). Other factors, such as the unilateral crowding caused by an asymmetric release of ova, may act primarily on the pups occupying one horn. The relative contributions of these local and systemic factors to embryonic survival were investigated by comparing litters carried entirely in one uterine horn with litters distributed across both.

\section{Materials and Methods}

\section{Animals}

Sprague-Dawley rats (Charles River, Portage, MI) were kept on a light schedule of $14 \mathrm{~h}$ light: $10 \mathrm{~h}$ dark. Food (Teklad $4 \%$ Rat-Mouse Diet) and water were provided ad libitum. Males were housed singly until mating. Females were housed in groups until being assigned to an experimental condition, then housed singly for at least 4 days before mating. Their oestrous cycles were monitored by daily vaginal lavage. At mating, males were $164 \pm 7$ days old and females were $180 \pm 7$ days old.

\section{Induction of one-horned implantation}

A silk suture was placed in one of the uterine horns of dams before mating to induce one-horned implantation, causing local sterility by the mechanism likely to be responsible for spontaneous unilateral implantation. Routine postpartum necropsies occasionally reveal materials retained in one horn after parturition that in life would have resulted in inflammation making that horn hostile to ova, spermatozoa and embryos (Parr, 1970). A silk suture intrauterine device (IUD) mimics this contraceptive effect by eliciting mild inflammation (Smeak, 1990) that leaves the contralateral horn unaffected.

Intrauterine devices were inserted by the protocol of Doyle and Margolis (1964). Female rats $(n=25)$ were anaesthetized by an i.p. injection of $65 \mathrm{mg}$ ketamine (Aveco Co., Fort Dodge, IA) and $49 \mathrm{mg}$ xylazine (American Animal Health, Wisner, NE) per kg body weight. Briefly, the ovarian end of one uterine horn was externalized and a $0.5 \mathrm{~cm}$ length of 3-0 silk suture was introduced into the lumen. A knot secured the suture against the serosal surface of the horn, and the cut end of the suture hung freely in the lumen of the horn. Surgeries were counterbalanced for left and right uterine horns.

\section{Cyclic and postpartum oestrous matings}

Males and females were paired for the cyclic oestrous mating 1 day before the day of proestrus in the female. Pairs $(n=35)$ mated in $1.2 \mathrm{~m} \times 1.2 \mathrm{~m}$ arenas designed to simulate the spacial complexity of a natural habitat (Bacon and McClintock, 1994). After mating, each rat was housed singly until day 21 of gestation (where day 1 was a sperm-positive vaginal lavage). The sire and dam were then returned to the mating arena so that the female could give birth and mate during her postpartum oestrus. One day after postpartum mating, the newborn suckling litter was removed. At the birth of the second (postpartum oestrous-conceived) litter, the pups were counted and sexed by measuring ano-genital distance.

\section{Necropsy}

Dams were necropsied 4 days after delivering their postpartum oestrous-conceived litter (34 of 35 dams delivered). The number of corpora lutea formed during the most recent pregnancy and the number of metrial glands from each of the cyclic oestrous- and postpartum oestrousconceived litters were counted. The number of corpora lutea (formed by those ova that mature before fertilization) provides an estimate of maximum litter size at conception. Metrial glands form in response to blastocyst attachment on day 5 of gestation (Seyle and McKeown, 1935; Martel et al., 1984) but persist whether or not the embryo survives, indicating the number of embryos that attached and induced the uterine decidual reaction.

\section{Two morphological classes of metrial glands}

At postpartum necropsy, two sets of metrial glands were visible on the uterus: large yellow-brown sites from the recent postpartum oestrous pregnancy and small, flat, brown sites from the previous (cyclic oestrous) pregnancy. Within the most recent (postpartum oestrous) set of metrial glands, there were two morphologically distinct subtypes. The first 
type, full postpartum oestrous metrial glands, were visible on the outside of the uterus as raised yellow nodules flecked with brown pigment, measuring approximately $5 \mathrm{~mm}$ in diameter on day 4 postpartum. However, there were also slightly smaller metrial glands that clearly belonged to the postpartum oestrous set but were morphologically distinct. These partial postpartum oestrous metrial glands were smaller than the full glands $(3.35 \pm 0.15 \mathrm{~mm})$, flat, and uniformly yellow (Fig. 1).

The interiors of partial and full postpartum oestrous metrial glands were also distinctive. When the luminal face of each metrial gland was exposed by slitting the uterine horn open, full postpartum oestrous glands formed small puckers of tissue with brown centres. Partial postpartum oestrous glands were smaller and unpuckered, with a pure yellow centre like the yolk of a fried egg (Fig. 2). Neither partial nor full postpartum oestrous metrial glands could be mistaken for cyclic oestrous sites, which formed small brown smudges on the interior of the horn and were markedly smaller on the outside $(2.10 \pm 0.06 \mathrm{~mm})$ than either type of postpartum oestrous gland.

Partial metrial glands have been noted by other investigators (Krackow, 1992; Huggett and Pritchard, 1945). They are often called 'resorptions', as they mark the loss (and subsequent re-absorption by the mother) of an embryo before full metrial gland development on day 14 of pregnancy.

\section{Information available on prenatal loss}

Corpora lutea and both types of metrial gland were assessed for postpartum oestrous pregnancies. Thus, prenatal loss from postpartum oestrous litters could be assigned to three periods: (a) pre-attachment loss of ova or early embryos (corpora lutea minus metrial glands); (b) early post-attachment loss of embryos (partial metrial glands); and (c) late post-attachment loss of embryos or fetuses (pups born minus full metrial glands). Only the total number of metrial glands could be assessed for cyclic oestrous pregancies and, thus, only overall post-attachment loss was determined.

\section{Statistical analysis}

Means and standard errors are reported. Sex ratio data were analysed after Freeman-Tukey transformation (Zar, 1984), but untransformed values are used in tables and figures for clarity.

\section{Results}

\section{Effect of unilateral implantation in postpartum oestrous pregnancy}

When they were induced by an IUD, unilateral embryo attachment and implantation did not cause litter sex ratio bias. Within unilaterally implanted litters, those carried entirely in the right horn were indistinguishable from those carried entirely in the left horn (Table 1). Left- and rightimplanted unilateral litters were close to identical in ovulation number, litter size at attachment, size at birth and sex ratio at birth.

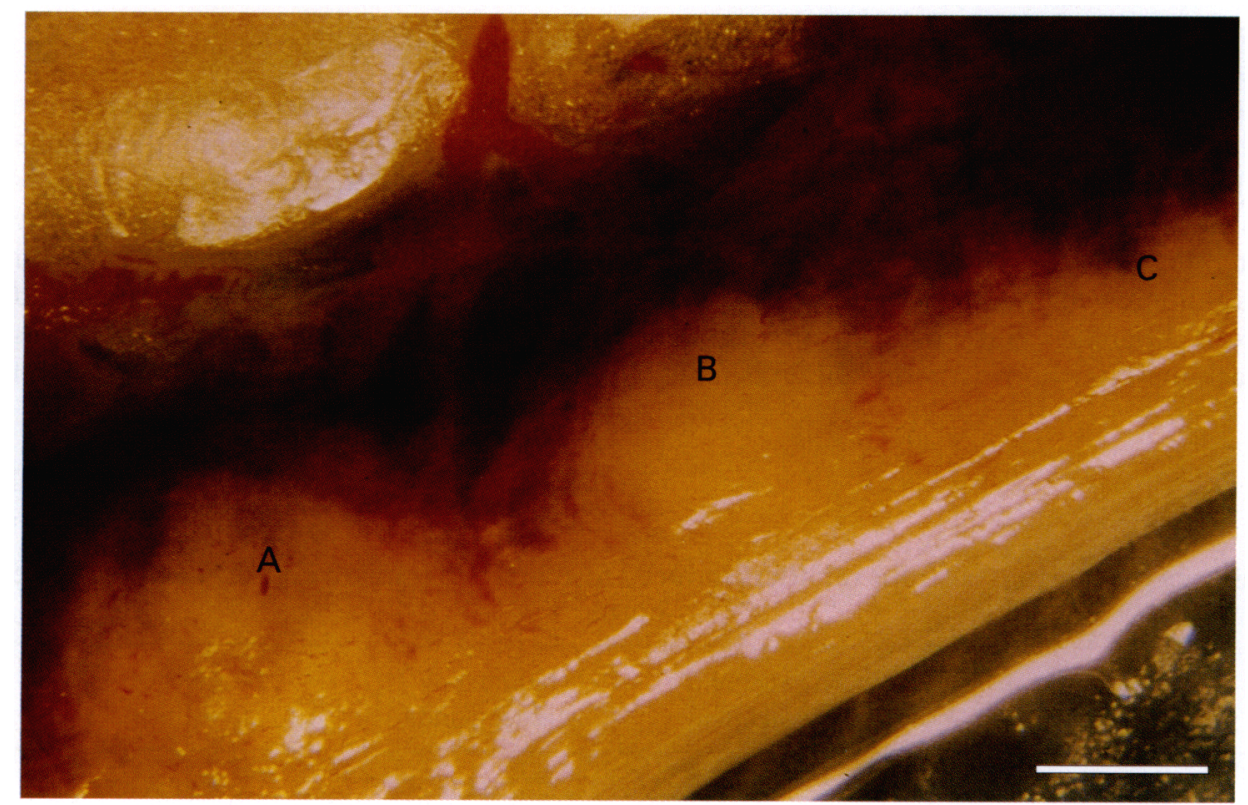

Fig. 1. Metrial glands on the outside of the postpartum rat uterus. This segment of the mesometrial edge of a uterine horn on the fourth day after the delivery of a postpartum oestrous litter shows: (A) a full metrial gland from the most recent (postpartum oestrous) pregnancy; (B) a partial metrial gland from the most recent (postpartum oestrous) pregnancy; and (C) a small, dark metrial gland from the previous (cyclic oestrous) pregnancy. Scale bar represents $3 \mathrm{~mm}$. 


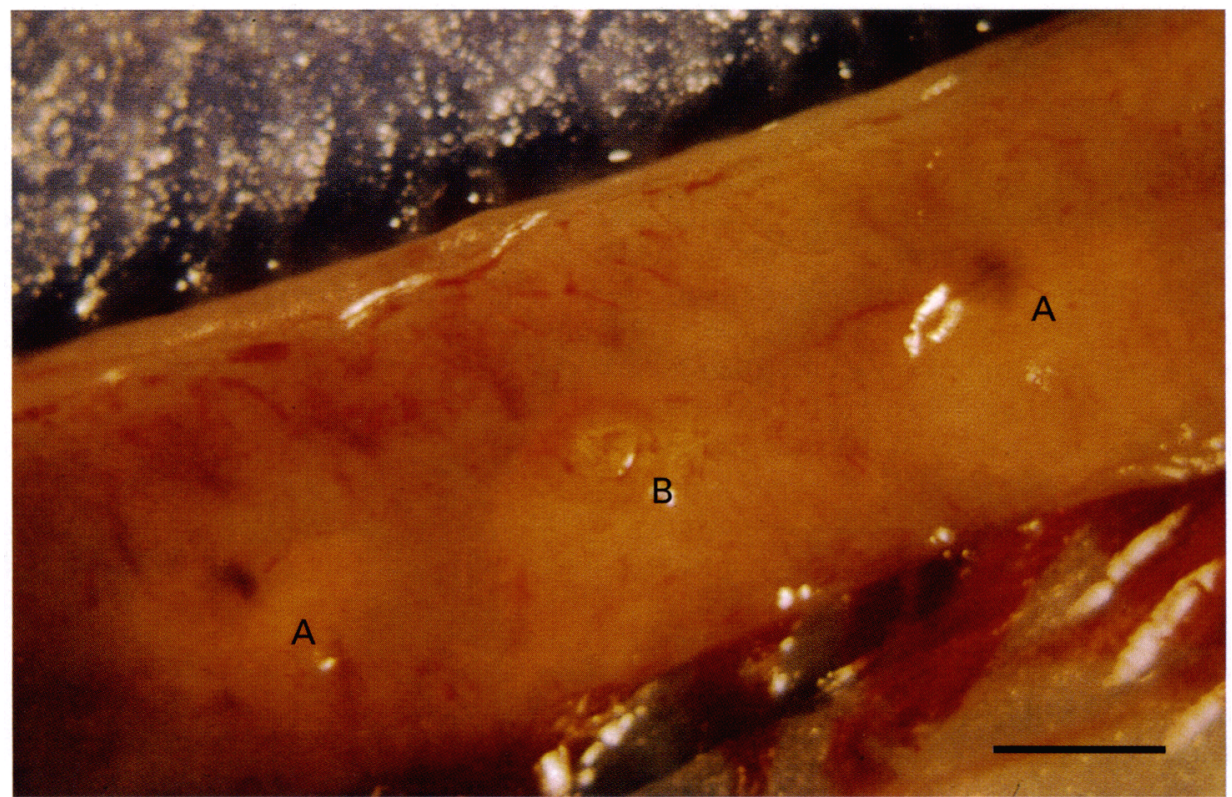

Fig. 2. Endometrial surface of metrial glands in the postpartum rat uterus. This uterus has been slit open along its antimesometrial border on day 4 after delivery, exposing the inner surfaces of the metrial glands. Two types of metrial gland are visible, both stemming from the most recent pregnancy. The two glands labelled (A) are full metrial glands, each forming a small pit with a dark brown centre. (B) is the very different partial metrial gland, with the yellow, open centre which gives it the look of a fried egg. Scale bar represents $3 \mathrm{~mm}$.

Moreover, the sex ratio of litters from induced unilateral pregnancies was no different from that of the bilaterally implanted litters in the present study (unilateral postpartum oestrous litter sex ratio $=0.431 \pm 0.053$; bilateral postpartum oestrous litter sex ratio $=0.474 \pm 0.034 ; t=0.56$, not significant), indicating that surgery itself had no effect on sex ratio bias. The outcome of pregnancy per gravid horn was the same whether or not the contralateral horn had carried pups (Table 2). Although litters carried in uteri unilaterally sterilized by an IUD were smaller than litters implanting bilaterally $(6.2 \pm 0.5$ pups in unilateral postpartum oestrous litters versus $13.1 \pm 1.3$ pups in bilateral postpartum oestrous litters; $t=5.15, P \leq 0.0005)$, rates of ovulation and attachment per horn were indistinguishable, as were rates of pre-attachment and early post-attachment loss (Table 2).

\section{Oestrous condition}

Fewer males were born in postpartum oestrous litters than in cyclic oestrous litters, while the number of females born remained constant. This postpartum decrease in male pups was particularly pronounced in bilaterally implanted litters (Fig. 3), and made postpartum oestrous litters significantly more female biased than cyclic oestrous litters overall (cyclic oestrous litter sex ratio $=0.539 \pm 0.034$; postpartum oestrous litter sex ratio $=0.459 \pm 0.040$; paired one-tailed $t=1.88, P \leq$

Table 1. Comparison of postpartum oestrous rat litters induced to attach and implant entirely in either the left or right uterine horns

\begin{tabular}{lcccc}
\hline Horn implanted & $\begin{array}{c}\text { Number of } \\
\text { gravid horns }\end{array}$ & $\begin{array}{c}\text { Number of } \\
\text { corpora lutea }\end{array}$ & $\begin{array}{c}\text { Number of } \\
\text { metrial glands }\end{array}$ & $\begin{array}{c}\text { Number of } \\
\text { pups born }\end{array}$ \\
\hline Left & 9 & $12.4 \pm 1.6$ & $7.7 \pm 1.0$ & $6.3 \pm 0.8$ \\
Right & 15 & $11.1 \pm 0.6$ & $7.7 \pm 0.6$ & $6.1 \pm 0.7$ \\
Student's $t$ test & - & $t=0.77, \mathrm{NS}$ & $t=0.06, \mathrm{NS} \quad$ & $0.442 \pm 0.071$ \\
\hline
\end{tabular}

"Ninety-six per cent ( 24 of 25$)$ of dams fitted with intrauterine devices gave birth to postpartum-conceived litters, each of which implanted entirely in the horn contralateral to the intrauterine device.

NS, not significant. 
Table 2. Corpora lutea and metrial glands per uterine horn in unilaterally and bilaterally implanting rat litters

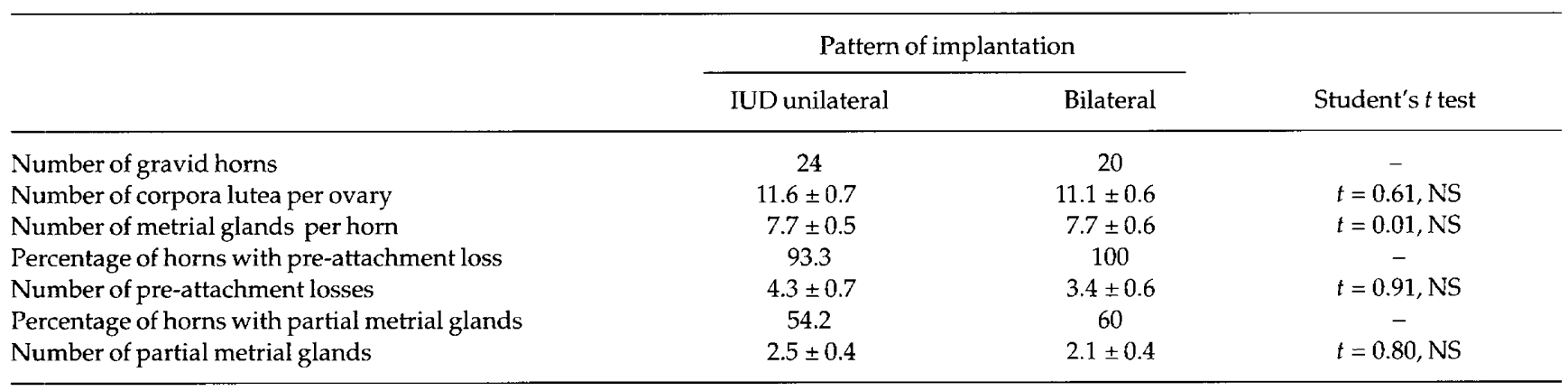

NS, not significant.

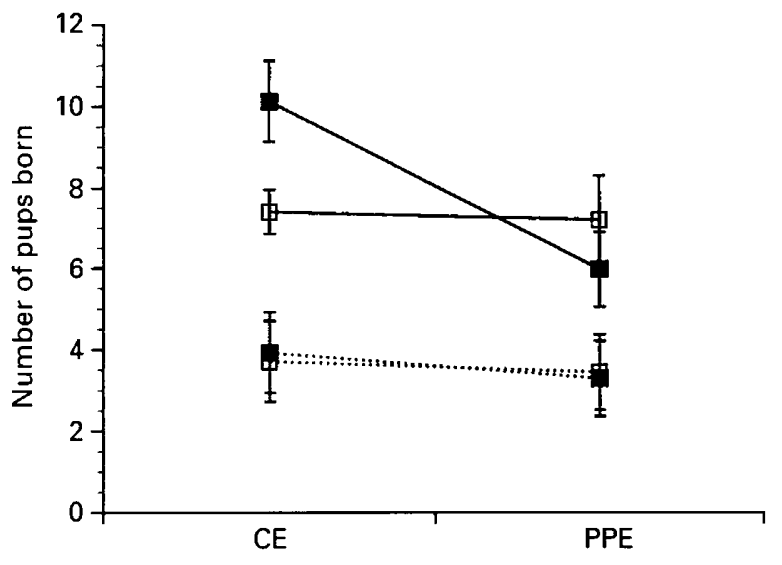

Oestrous condition at conception

Fig. 3. The decrease in male pups born in postpartum oestrousconceived rat litters was most pronounced in litters that had implanted bilaterally. Interaction plots for male ( $\square$ ) and female ( $\square$ ) pups conceived in a cyclic oestrus (CE) and in a postpartum oestrus (PPE) are combined. Nine bilateral (-) and 19 unilateral (----) litters had reliable sex ratio data in both cyclic oestrus and postpartum oestrus. Males: in bilateral litters $10.1 \pm 1.0$ cyclic oestrus versus $5.9 \pm 0.6$ postpartum oestrus; in unilateral litters $3.9 \pm 0.4$ versus $3.2 \pm 0.4$ postpartum oestrus; main effect of implantation pattern $F(1,25)=51.6, \quad P \leq 0.0001$, main effect of oestrous condition $F(1,25)=14.4$, interaction $F(1,25)=12.6, P \leq 0.01$. Females: bilateral litters $7.4 \pm 0.9$ cyclic oestrus versus $7.1 \pm 1.1$ postpartum oestrus; unilateral litters $3.7 \pm 0.4$ cyclic oestrus versus $3.4 \pm 0.3$ postpartum oestrus; main effect of implantation pattern $F(1,25)=42.2, P \leq 0.0001$, main effect of oestrous condition $F(1,25)=0.27$, not significant, interaction $F(1,25)=0.003$, not significant.

0.04). Litters conceived in a postpartum oestrus were smaller than cyclic oestrous litters, a difference also most pronounced in the bilaterally implanted litters (Table 3).

Because the postpartum oestrous litters were statistically no smaller at metrial gland formation (Table 3), the size deficit at birth must have stemmed from a higher rate of postattachment fetal loss in postpartum oestrous litters. Indeed, postpartum oestrous litters lost more embryos after attachment than did cyclic oestrous litters $(1.9 \pm 0.3$ lost in postpartum oestrus; $1.0 \pm 0.3$ in cyclic oestrus; $t=2.17, P \leq 0.04$ ).
Moreover, within these postpartum oestrous litters, loss between metrial gland formation and birth (calculated by subtracting the number of postpartum oestrous pups born from the total number of postpartum oestrous metrial glands) was highly correlated with the number of partial metrial glands found in the uterus $\left(R^{2}=0.90\right.$; Fig. 4). Therefore, most of the offspring lost in postpartum oestrous litters were accounted for by these partial glands, and died between attachment (day 5) and full metrial gland development (day 14).

\section{Midpregnancy loss in postpartum oestrus and litter sex ratio}

Partial metrial glands were closely associated with litter sex ratio bias. Litters born to dams with partial metrial glands were significantly more female biased than were litters born to dams without them (Fig. 5). Moreover, in the IUD-induced unilateral litters, there was a linear relationship between midpregnancy loss and sex ratio: as the number of partial metrial glands increased, litter sex ratio became more biased toward females (Fig. 6a). This relationship was not evident in bilateral pregnancies, in which any link between loss and sex ratio biasing in each horn of a bilateral litter was obscured at birth when the contents of the two horns mixed (Fig. 6b).

Although midpregnancy loss was associated with litter sex ratio biasing, there were other opportunities to bias the sex ratio of litters conceived post partum through loss. Offspring were lost early, before metrial gland formation, and late, after the gland was fully formed. However, preattachment loss was so universal that its possible impact on litter sex ratio could not be determined. More than $90 \%$ of postpartum litters ( 28 of 30 ) lost embryos before attachment. In contrast, late post-attachment loss was so rare that it could be, at best, a weak biasing mechanism. Less than $7 \%$ of litters (2 of 30 ) lost fetuses after full metrial gland formation.

\section{Correlates of partial metrial glands in postpartum oestrus conceptions}

The risk of having partial metrial glands was more closely related to the number attaching in a horn than to the number attaching in a litter (Fig. 7a versus $7 b$ ). Partial metrial glands 
Table 3. Comparison of intrauterine device (IUD)-induced unilateral litters and bilateral litters across cyclic (CE) and postpartum oestrous (PPE) conditions in rats

\begin{tabular}{|c|c|c|c|c|c|}
\hline Pattern of implantation & Sample size $\mathrm{a}^{\mathrm{a}}$ & $\mathrm{CE}$ & PPE & Repeated measures ANOVA ${ }^{b}$ & $P$ value \\
\hline \multicolumn{6}{|l|}{ Pups born } \\
\hline IUD unilateral & 24 & $7.0 \pm 0.5$ & $6.2 \pm 0.5$ & $\begin{array}{l}F(1,31)=97.06 \\
F(1,31)=9.34\end{array}$ & $\begin{array}{l}\leq 0.0001 \\
\leq 0.0046\end{array}$ \\
\hline Bilateral & 9 & $17.0 \pm 0.8$ & $13.1 \pm 1.3$ & $F(1,31)=6.23$ & $\leq 0.0181$ \\
\hline \multicolumn{6}{|l|}{ Metrial glands } \\
\hline IUD unilateral & 24 & $7.8 \pm 0.5$ & $7.7 \pm 0.5$ & $\begin{array}{l}F(1,31)=133.08 \\
F(1,31)=1.126\end{array}$ & $\begin{array}{l}\leq 0.0001 \\
\leq 0.2969\end{array}$ \\
\hline Bilateral & 9 & $17.6 \pm 0.9$ & $15.6 \pm 1.0$ & $F(1,31)=2.233$ & $\leq 0.1452$ \\
\hline \multicolumn{6}{|l|}{ Sex ratio } \\
\hline IUD unilateral & 19 & $0.523 \pm 0.043$ & $0.453 \pm 0.055$ & $\begin{array}{l}F(1,25)=0.464 \\
F(1,25)=3.390\end{array}$ & $\begin{array}{l}\leq 0.50 \\
\leq 0.08\end{array}$ \\
\hline Bilateral & 8 & $0.578 \pm 0.051$ & $0.472 \pm 0.042$ & $F(1,25)=0.007$ & $\leq 0.78$ \\
\hline
\end{tabular}

"Repeated-measures analysis restricts the sample to those cases in which reliable data were available for both the CE- and PPE-conceived litters. All (24 of 24) unilateral litters and 9 of 10 bilateral litters had reliable information on the number of pups born in both CE- and PPE-conceived litters; 19 of 24 unilateral litters and 8 of 10 bilateral litters had reliable data on litter sex ratio in both CE- and PPE-conceived litters.

${ }^{b} F$ values for each repeated measures ANOVA are reported as follows: main effect of pattern of implantation (unilateral/bilateral), main effect of oestrous condition, effect of interaction.

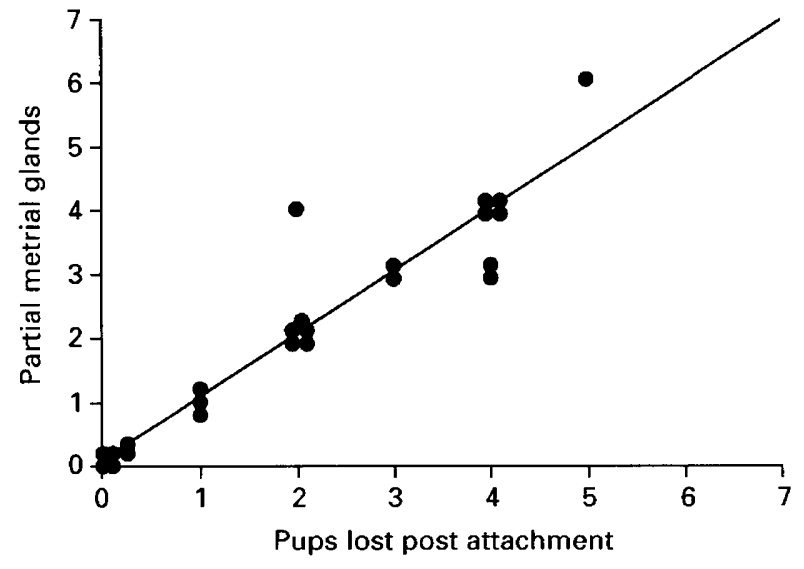

Fig. 4. Post-attachment loss in rats was tightly correlated with the presence of partial metrial glands. Pups calculated missing between attachment and birth (total metrial glands - pups born) were almost all accounted for by partial metrial glands. $y=0.078+0.982 x, R^{2}=$ $0.90, P \leq 0.0001$. Because partial glands were first noted when some necropsies were already complete, data reflect the 30 of 34 postpartum necropsies for which data on partial metrial glands were gathered.

were found in those horns that exceeded a minimum size threshold (Fig. 7a). In fact, any horn in which at least the median number of embryos had attached was likely to have partial metrial glands (median number of metrial glands per horn $=8 ; 81 \%$ of horns with $\geq 8$ metrial glands had partials, $19 \%$ of horns with $\leq 7$ metrial glands had partials; chisquared adjusted for continuity $=5.572, P \leq 0.018, n=40$ horns).

Because uterine horns with partial metrial glands were significantly larger at attachment than were horns without

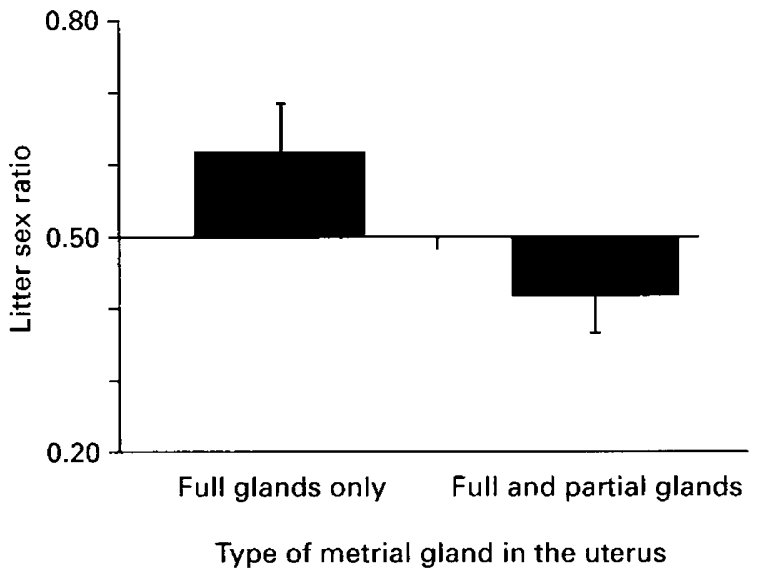

Fig. 5. Postpartum-conceived rat litters carried in uteri with partial metrial glands were more female biased than litters carried in uteri without partial metrial glands. The litters without partial metrial glands had a mean sex ratio of $0.62 \pm 0.07$, the litters with partials had a mean sex ratio of $0.41 \pm 0.05$ (one-tail $t=1.95, P \leq 0.03$ ).

( $8.8 \pm 0.3$ glands versus $6.6 \pm 0.8 ; t=2.8, P \leq 0.01)$, the surfeit of embryos in horns with loss should have minimized the impact of the loss on litter size at birth. In fact, limited data from the unilaterally implanting litters support this hypothesis. Dams with partial metrial glands delivered litters no smaller than those born to dams without partials $(6.2 \pm 0.9$ pups born when there were partials, $n=13 ; 7.0 \pm$ 0.6 pups born when there were no partials, $n=7, t=0.77$, not significant). 
(a)

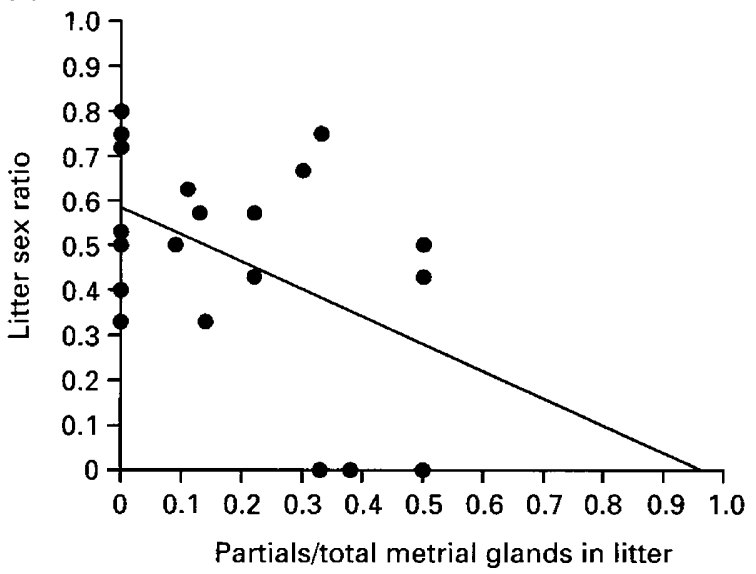

(b)

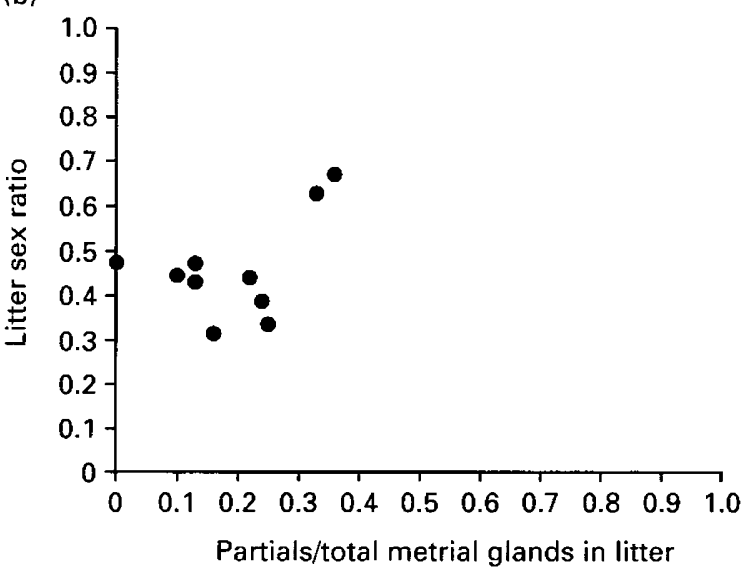

Fig. 6. In rats, as the percentage of the litter lost to partial metrial glands increased, the female bias increased in unilateral litters but not in bilateral litters. (a) Unilateral litters, $y=0.864-0.633 x, R^{2}=$ $0.179, P \leq .04$. (b) Bilateral litters, $y=0.653+0.454 x, R^{2}=0.121$, not significant.

\section{Discussion}

When a dam loses her nursing litter after conceiving in a postpartum oestrus, embryonic loss in midpregnancy biases the litter in utero toward females. In the present study, postpartum-conceived rat litters lost conceptuses at all stages of gestation, but only embryo loss between days 5 and 14 of pregnancy (indicated by anatomically distinct partial metrial glands in the postpartum uterus) was associated with sex ratio biasing. These findings confirm the link Krackow (1992) made in house mice between loss in midpregnancy (marked by anatomically distinct metrial glands) and litter sex ratio adjustment.

Those uterine horns that lost embryos in midpregnancy had started with more from the time of embryo attachment. Thus, when a surfeit of embryos attached, dams had the opportunity to bias litter sex ratio without appreciably decreasing the mean size of the liveborn litter. The risk of loss after attachment (and thus the opportunity for sex ratio biasing) correlated more closely with the number of embryos sharing the uterine horn than with the number in the litter, in

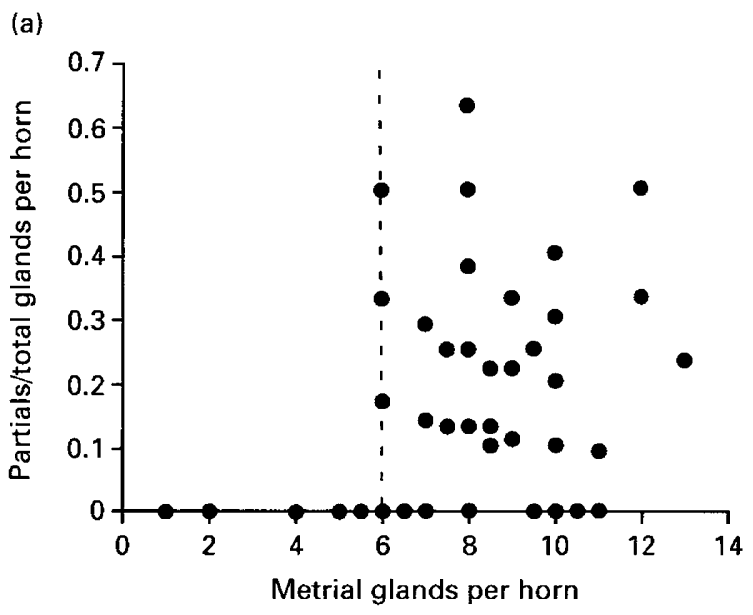

(b)

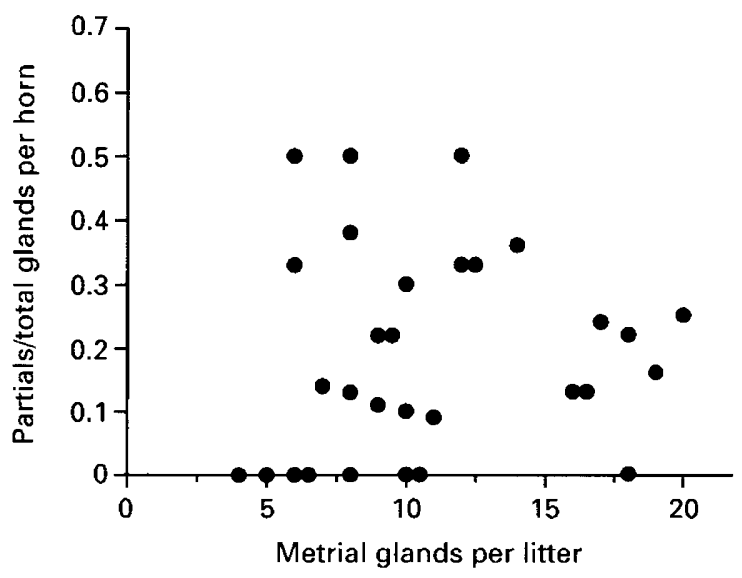

Fig. 7. In rats, the risk of partial metrial glands was correlated more closely with the number of metrial glands in the horn (a) than with the number in the litter $(b)$.

agreement with other findings in rodents. Within-horn factors can account for much of the variation seen in fetal and placental growth in mice (McCarthy, 1967; Barr et al., 1970) and, in rats, the distribution of embryos between the horns tends to even out over the course of pregnancy (Barr et al., 1970), consistent with the present finding that embryos are preferentially lost from more populated horns. Such withinhorn factors outweighed any effect of right-left uterine asymmetry on embryo survival. In the present study, left and right uterine horns were indistinguishable in their ability to carry pups of a given sex to term.

Male embryos are known to be more sensitive to the suboptimal conditions in a crowded uterine horn. Ward et al. (1977) found that the weight of male, but not female, rat fetuses was inversely related to the number of individuals sharing a horn during pregnancy. In many mammals, males have higher prenatal and postnatal mortality rates than females. In golden hamsters, a mother under social stress (experiencing the associated decrease in serum progesterone) will lose males preferentially in utero (Pratt and Lisk, 1991). In humans, most anatomically normal abortuses are male (Byrne and Warburton, 1987) and differential mortality is highest during the embryonic phase 
of pregnancy (Kellokumpu-Lehtinen and Pelliniemi, 1984). Male infants are also less likely than females to survive premature delivery (Holtrop et al., 1994). In several species, including rats, mice and humans, an excess of males at birth (King, 1921; Ciocco, 1938) is gradually attenuated by higher male mortality until maturity (James, 1987).

The reason why male mortality is higher is unknown. The lack of two $X$ chromosomes may increase the chance that a male will fall victim to recessive lethals. There are also sex differences in developmental rate that could affect survival. Males grow more rapidly than females, and the differences are apparent by the blastocyst stage, well before sexual differentiation in mice and rats (Seller and Perkins-Cole, 1987; Burgoyne, 1993; Valdivia et al., 1993) and cows (Avery et al., 1992). Males may place more demands on maternal physiology than females to support this higher growth and thus may be more sensitive to any shortages.

In the present study, male embryos were lost by dams that conceived immediately after a previous birth and did not suckle a litter during gestation. When a dam is able to keep and suckle her firstborn litter, lactation delays the attachment and implantation of the blastocysts in utero by up to 3 weeks (Vorherr et al., 1984). This delay prolongs the period available for uterine involution, the healing process that repairs the scarred endometrium and prepares it for the next pregnancy. In humans, a short interval between birth and an ensuing conception is associated with greater risk of prenatal mortality (Rawlings et al., 1995). The abbreviated postpartum recovery period in non-lactating dams may make early pregnancy more difficult for the developing embryo. In the present study, the shorter postpartum recovery period could be most injurious to those embryos (males) with the greatest need for maternal resources.

This research was supported by grants from the National Institute of Mental Health: an NRSA (MH10801) to S. J. Bacon and a MERIT award (R37 MH41788) to M. K. McClintock. The authors thank Alexis Papageorge for technical assistance.

\section{References}

Avery B, Jorgensen CB, Madison V and Greve T (1992) Morphological development and sex of bovine in vitro fertilized embryos Molecular Reproduction and Development 32 265-270

Bacon SJ and McClintock MK (1994) Multiple factors determine the sex ratio of postpartum-conceived Norway rat litters Physiology and Behavior 56 359-366

Barr M, Jr, Jensh RP and Brent RL (1970) Prenatal growth in the albino rat: effects of number, intrauterine position and resorptions American Journal of Anatomy 128 413-428

Blumberg MS, Mennella JA, Moltz H and McClintock MK (1992) Facultative sex-ratio adjustment in Norway rats: litters born asynchronously are female biased Behavioral Ecology and Sociobiology 31 401-408

Burgoyne PS (1993) A Y-chromosomal effect on blastocyst cell number in mice Development 117341-345

Byme J and Warburton D (1987) Male excess among anatomically normal fetuses in spontaneous abortions American Journal of Medical Genetics 26 605-611

Calhoun JB (1962) The Ecology and Sociology of the Norway Rat Publication Number 1008. United States Public Health Service, Washington DC

Ciocco A (1938) Variation in the sex ratio at birth in the United States Human Biology 1036-64

Clark MM, Ham M and Galef BG (1994) Differences in the sex ratios of offspring originating in the right and left ovaries of Mongolian gerbils (Meriones unguiculatus) Journal of Reproduction and Fertility 101 393-396

Diskin MG and Sreenan JM (1980) Fertilization and embryonic mortality rates in beef heifers after artificial insemination Journal of Reproduction and Fertility 59 463-468

Doyle LL and Margolis AJ (1964) Intrauterine foreign body I. Effect on reproductive processes in the rat Fertility and Sterility 15 597-606

Edmonds DK, Lindsay KS, Miller JF, Williamson E and Wood PJ (1982) Early embryonic mortality in women Fertility and Sterility 38 447-453

Gosling LM (1986) Selective abortion of entire litters in the coypu: adaptive control of offspring production in relation to quality and sex American Naturalist 127 772-795

Guerrero R (1974) Association of the type and time of insemination within the menstrual cycle with the human sex ratio at birth New England Journal of Medicine 291 1056-1059

Harlap S (1979) Gender of infants conceived on different days of the menstrual cycle New England Journal of Medicine 300 1445-1448

Hedricks C and McClintock MK (1990) Timing of insemination is correlated with the secondary sex ratio of Norway rats Physiology and Behavior 48 625-632

Holtrop PC, Ertzbischoff LM, Roberts CL, Batton DG and Lorenz RP (1994) Survival and short-term outcome in newborns of 23 to 25 weeks' gestation American Journal of Obstetrics and Gynecology 170 1266-1270

Hornig LE and McClintock MK (1994) Unmasking sex ratio biasing through targeted analysis Animal Behaviour 47 1224-1226

Hornig LE and McClintock MK (1996) Male sexual rest affects litter sex ratio of newborn Norway rats Animal Behaviour 51 991-1005

Huck UW, Lisk RD, Miller KS and Bethel A (1988) Progesterone levels and socially induced implantation failure and fetal resorption in golden hamsters (Mesocricetus auratus) Physiology and Behavior 44 321-326

Huck UW, Seger J and Lisk RD (1990) Litter sex ratios in the golden hamster vary with time of mating and litter size and are not binomially distributed Behavioral Ecology and Sociobiology 2699-109

Huggett A St G and Pritchard JJ (1945) Experimental foetal death: the surviving placenta Proceedings of the Royal Society of Medicine 38 261-266

James WH (1980) Time of fertilisation and sex of infants Lancet 1124-1126

James WH (1987) The human sex ratio 1. A review of the literature Human Biology 59 721-752

Kellokumpu-Lehtinen P and Pelliniemi LJ (1984) Sex ratio of human conceptuses Obstetrics and Gynecology 64 220-222

King HD (1921) A comparative study of the birth mortality in the albino rat and in man Anatomical Record 20 321-354

Krackow S (1990) Sex-specific embryonic mortality during concurrent pregnancy and lactation in house mice Journal of Experimental Zoology 256 106-112

Krackow S (1992) Sex ratio manipulation in wild house mice: the effect of fetal resorption in relation to the mode of reproduction Biology of Reproduction 47 541-548

Kruuk LE, Clutton-Brock TH, Albon SD, Pemberton JM and Guinness FE (1999) Population density affects sex ratio variation in red deer Nature 399 459-461

Long JA and Evans HM (1921) Proportion of ova producing full-term young in the rat Anatomical Record 21 56-57

McCarthy JC (1967) Effects of litter size and maternal weight on foetal and placental weight in mice Journal of Reproduction and Fertility 14 507-510

McClure PA (1981) Sex-biased litter reduction in food restricted wood rats (Neotoma floridana) Science 211 1058-1060

MacDowell EC (1924) A method of determining the prenatal mortality in a given pregnancy of a mouse without affecting its subsequent reproduction Anatomical Record 27 329-336

MacDowell EC and Lord EM (1926) The relative viability of male and female mouse embryos American Journal of Anatomy 37 127-140

Martel D, Monier M-N, Psychoyos A and deFeo V (1984) Estrogen and progesterone receptors in the endometrium, myometrium and metrial gland of the rat during the decidualization process Endocrinology $\mathbf{1 1 4}$ $1627-1634$

Mennella JA, Blumberg MS, McClintock MK and Moltz H (1990) Inter-litter competition and communal nursing among Norway rats: advantages of birth synchrony Behavioral Ecology and Sociobiology 27 183-190

Miller JF, Williamson E, Glue J, Gordon YB, Grudzinskas JG and Sykes A (1980) Fetal loss after implantation: a prospective study Lancet 554-556

Parr EL (1970) Leucocytes and infertility Journal of Reproduction and Fertility Supplement $10153-170$ 
Pratt NC and Lisk RD (1991) Role of progesterone in mediating stress-related litter deficits in the golden hamster (Mesocricetus auratus) Journal of Reproduction and Fertility 92 139-146

Pratt NC, Huck UW and Lisk RD (1989) Do pregnant hamsters react to stress by producing fewer males? Animal Behavior 37 155-157

Rawlings JS, Rawlings VB and Read JA (1995) Prevalence of low birth weight and preterm delivery in relation to the interval between pregnancies among white and black women New England Journal of Medicine 332 69-74

Roberts CJ and Lowe CR (1975) Where have all the conceptions gone? Lancet 498-499

Roche JF, Bolandl MP and McGeady TA (1981) Reproductive wastage following artificial insemination of heifers Veterinary Record 109 401-404

Seller MJ and Perkins-Cole KJ (1987) Sex difference in mouse embryonic development at neurulation Journal of Reproduction and Fertility 79 159-161

Seyle $\mathbf{H}$ and McKeown T (1935) Studies on the physiology of the maternal placenta in the rat Proceedings of the Royal Society of London Series B 119 1-31

Smeak DD (1990) Selection and use of currently available suture materials. In Current Techniques in Small Animal Surgery pp 34-39 Eds M) Bojrab, SJ Birchard and JJL Tomlinson. Lea and Febiger, Philadelphia, PA
Trivers RL and Willard DE (1973) Natural selection of parental ability to vary the sex ratio of offspring Science 179 90-91

Valdivia RP, Kunieda T, Azuma S and Toyoda Y (1993) PCR sexing and developmental rate differences in preimplantation mouse embryos fertilized and cultured in vitro. Molecular Reproduction and Development 35 121-126

Vorherr H, Vorherr UF, Pathak D, Reyes E, Jordan S and Messer RH (1984) Embryonic/fetal growth following suckling-induced delay of implantation American Journal of Obstetrics and Gynecology 149 209-214

Warburton D (1987) Reproductive loss: how much is preventable? New England Journal of Medicine 316158-160

Ward WF, Karp CH and Aceto H, Jr (1977) Developmental effects of the uterine environment: dependence on fetal sex in rats Journal of Reproduction and Fertility 50 269-274

Wathes DC (1992) Embryonic mortality and the uterine environment Journal of Endocrinology 134 321-325

YoungLai EV, Pan C-C and Bhavnani BR (1981) Asymmetric distribution of male and female foetuses in the pregnant rabbit uterus Experientia 37 690-691 Zar JH (1984) Biostatistical Analysis Prentice-Hall, New Jersey 